\title{
Stimulus size and visual angle in a cue-reduced experimental setting
}

\author{
ROBERT RIX, ZITA E. TYER, and ROBERT PASNAK \\ George Mason University, Fairfax, Virginia 22030
}

\begin{abstract}
The effect of stimulus size and visual angle on the perception of luminescent objects was studied. Forty subjects were asked to estimate the size of one of four stimulus objects viewed through a pinhole eyepiece. Their estimates corresponded to the retinal angle, rather than the metric size of the stimuli. The probable roles of the specific distance tendency and aerial perspective as perceptual anchors that govern these estimates were discussed.
\end{abstract}

In independently conducted research, Baird (1964), Gogel (1969), and Gogel and Sturm (1971) reported that, in the absence of uncontrolled depth cues, retinal image, not metric size, is discriminated. A more recent investigation reported by Fitzpatrick, Pasnak, and Tyer (1982), however, indicated that retinal image was not discriminated in a cue-reduced experimental situation. Fitzpatrick et al. (1982) used a pinhole eyepiece to control for accommodation and monocular accommodative convergence. This method of cue control was also employed by Gogel and Sturm (1971), but it produced conflicting results in their situation. The present investigation was designed to test the effect of stimulus size and retinal angle on size perception using the pinhole eyepiece method of cue control. Comparisons that facilitate a statistical assessment of the success of cue reduction were incorporated in the experimental design.

\section{METHOD}

\section{Subjects}

Subjects were 40 volunteers who were naive regarding the nature of the experiment and were not familiar with the experimental suite. Only individuals with $20 / 30$ vision or better in one eye as measured by a Snellen Eye Chart were used as subjects, and none wore corrective lenses.

\section{Apparatus}

The lighttight laboratory suite was internal to other laboratory rooms and separated from them by an exterior hallway so that subjects could gain no idea of the shape or size of the experimental chamber. The experimental chamber measured $18.24 \mathrm{x}$ $2.74 \times 3.04 \mathrm{~m}$.

Accommodation cues were controlled by mounting a $1.0-\mathrm{mm}$ pinhole eyepiece in the door of the experimental chamber $1.17 \mathrm{~m}$ from the floor. The effect of mounting the eyepiece in the closed door was to deny subjects an opportunity to estimate the size of the chamber.

Four stimuli were constructed from luminescent strips (John Meshna, Inc., Lynn, Massachusetts) that emitted a uniform faint green glow when alternating current was applied to them. The stimuli's dimensions were (A) $2.54 \times .64 \mathrm{~cm}$, (B) $5.08 \times 1.27 \mathrm{~cm}$, (C) $20.53 \times 2.54 \mathrm{~cm}$, and (D) $41.06 \times$ $5.08 \mathrm{~cm}$.

All stimuli were mounted on wooden stands $1.17 \mathrm{~m}$ from the floor. A and B were placed 2.44 and $4.88 \mathrm{~m}$, respectively, from the subject's eye, subtending a visual angle of $1 \mathrm{deg} 12 \mathrm{~min}$. C and $\mathrm{D}$ were situated 4.88 and $9.75 \mathrm{~m}$, respectively, from the subject's eye, subtending a visual angle of $4 \mathrm{deg} 48 \mathrm{~min}$.

Prior to the experiment, brightness matches between all stimuli were determined by adjusting supply voltages to the strips using ac variacs. Luminance at the eyepiece was $-.03 \log \mathrm{fL}$. The low luminance, unfamiliar dimensions of the experimental chamber, and monocular pinhole eyepiece appeared to eliminate all depth cues except accommodation, which was held constant for all stimuli.

\section{Procedure}

Subjects were randomly assigned to view one stimulus object (determined via a Latin square design). They were seated on a metal stool before the pinhole eyepiece with the houselights turned off.

First, each subject was asked to estimate the size of the stimulus (verbal estimate). After the verbal estimate, a perceptualmotor estimate was taken. Subjects were asked to draw a line whose length was equivalent to their size judgment on a continuous roll of paper. The measured length of this line constituted a perceptual-motor estimate.

\section{RESULTS}

If control of distance cues were imperfect, metric size should be a usable cue in this experiment and the four means should show an ordinal relationship $(\mathrm{A}<\mathrm{B}<\mathrm{C}<\mathrm{D})$. Overall, this ordinal pattern was not observed, thus providing evidence that there were no functional depth cues. (While $\mathrm{C}$ and $\mathrm{D}$ show this ordinal pattern, as half of all comparisons must on a purely random basis, the difference is nonsignificant and well within the range of random variation. Hence, there is statistical evidence that any residual distance cues that may have existed did not produce differential distance estimates.)

The results also indicate that visual angle was an effective cue that governed size estimates. A two-factor analysis of variance revealed a significant difference between the collapsed conditions of $\mathrm{A}$ and $\mathrm{B}$, which were retinal equalities, and the collapsed conditions of $\mathrm{C}$ and $\mathrm{D}$, which were also retinal equalities, for both the verbal $[\mathrm{F}(1,38)=6.78, \mathrm{p}<.01]$ and perceptual-motor $[F(1,38)=4.20, p<.05]$ estimates. Further analysis revealed no significant difference between either of the 
Table 1

Mean Verbal and Perceptual-Motor (PM) Size Estimates in Inches

\begin{tabular}{cccccc}
\hline $\begin{array}{c}\text { Stimulus } \\
\text { Condition }\end{array}$ & $\begin{array}{c}\text { Stimulus } \\
\text { Size }\end{array}$ & \multicolumn{2}{c}{ Visual Angle } & $\begin{array}{c}\text { Verbal } \\
\text { Degrees }\end{array}$ & $\begin{array}{c}\text { PM } \\
\text { Estinutes }\end{array}$ \\
\hline Estimate & Estimate \\
\hline B & 2.54 & 1 & 12 & .53 & .47 \\
C & 5.08 & 1 & 12 & .47 & .31 \\
D & 20.32 & 4 & 48 & .95 & .69 \\
& 40.64 & 4 & 48 & 1.18 & .75 \\
\hline
\end{tabular}

retinal equalities $[\mathrm{A}$ and $\mathrm{B}, \mathrm{t}(18)=.293, \mathrm{p}>.05 ; \mathrm{C}$ and $\mathrm{D}, \mathrm{t}(18)=.822, \mathrm{p}>.05]$. Table 1 summarizes the means for all conditions.

\section{DISCUSSION}

The findings of this experiment indicate that subjects were able to discriminate retinal angle, not metric size, in a cuereduced experimental setting. These results contradict those of Fitzpatrick et al. (1982) and are congruent with those of other researchers (Baird, 1964; Gogel, 1969; Gogel \& Sturm, 1971).

An important difference between all of the experiments and that of Fitzpatrick et al. (1982) is the distances at which the stimulus objects were located. In the Fitzpatrick et al. (1982) study, stimuli were much closer to the subjects $(.76-1.49 \mathrm{~m})$, whereas in the present experiment, stimulus distance ranged from 2.44 to $4.88 \mathrm{~m}$, and even greater distances were employed in the other experiments cited. It may be that, at larger distances, the specific distance tendency (Gogel \& Tietz, 1973) acts as a perceptual anchor. Such an anchor may enable individ. uals to perceive retinal size, as Gogel (1969) suggests. Smaller distances, such as those employed by Fitzpatrick et al. (1982), may minimize the effect of such an anchor.

In addition to a possible minimization of the anchoring effect of the specific distance tendency, aerial perspective is greatly reduced when stimuli are proximal. This may be another part of the reason why subjects in the Fitzpatrick et al. (1982) study were unable to use visual angle as a cue. Still, the preponderance of the evidence indicates that, except in very limited circumstances, subjects are able to make size estimates on the basis of retinal size.

\section{REFERENCES}

Baird, J. C. Size of retinal image as a perceptual cue. Perceptual and Motor Skills, 1964, 18, 529-532.

Fitzpatrick, V., Pasnak, R., \& Tyer, Z. E. The effect of familiar size at familiar distances. Perception, 1982, 11, 85-91.

GooEL, W. C. The sensing of retinal size. Vision Research, 1969, 9, 1079-1094.

Gogel, W. C., \& Sturm, R. D. Directional separation and the size cue to distance. Psychologische Forschung, 1971, 35, 57-80.

Gogel, W. C., \& Tietz, J. D. Absolute motion parallax and the specific distance tendency. Perception \& Psychophysics, 1973, 13, 284-292.

(Received for publication December 21, 1982.) 